This item was submitted to Loughborough's Institutional Repository (https://dspace.lboro.ac.uk/) by the author and is made available under the following Creative Commons Licence conditions.

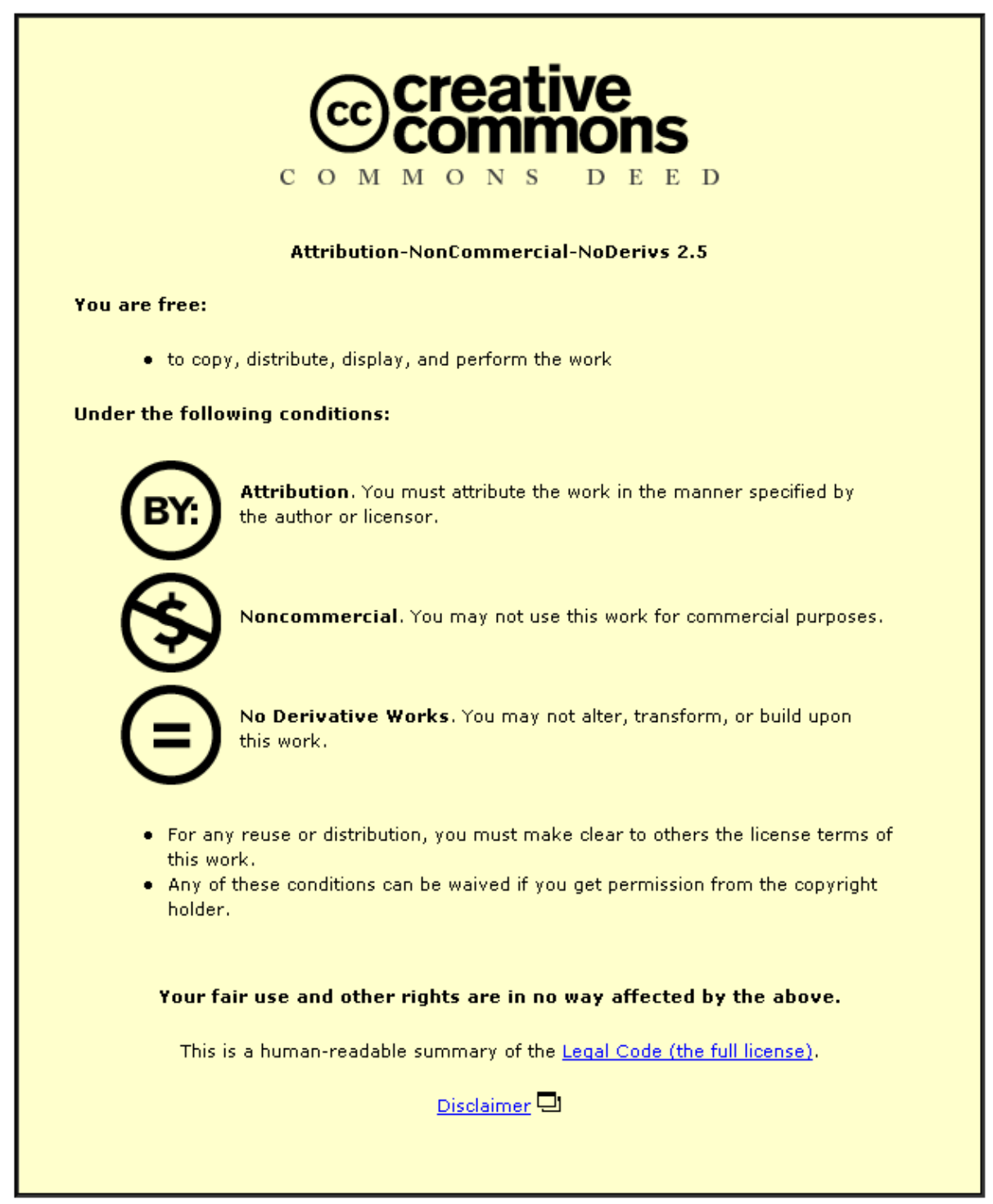

For the full text of this licence, please go to: http://creativecommons.org/licenses/by-nc-nd/2.5/ 
Mohammed A. Quddus Research Associate, Centre or Transport Studies, Department of Civil and Environmental Engineering, College London, Uk

\title{
Development of a vehicle emissions monitoring system
}

\author{
R. J. North, W. Y. Ochieng, M. A. Quddus, R. B. Noland and J. W. Polak
}

Investigation of vehicle emissions with an on-board emissions measurement system can provide a better understanding of how these emissions contribute to air pollution. This paper discusses the design and development by Imperial College London and industrial collaborators of a vehicle performance and emissions monitoring system, including its installation both on test vehicles allowing an interface with the engine management system and those that do not. Results from preliminary field trials and chassis dynamometer testing of the diesel test vehicle are presented. Good correlation between the monitoring system and reference measurements is observed, with differences in aggregate measurements of between $8 \%$ and $18 \%$ over a standard test cycle. The remote download and synthesis of navigation, performance and emissions data from an inuse vehicle was successfully achieved. This project has shown that it is possible to produce a system suitable for deployment for simultaneous studies over a wide area. However, the non-standard nature of engine management system interfaces for much of the European vehicle fleet presents a significant barrier to implementation. It is therefore recommended that European legislation be enforced to ensure standard interfaces on all new vehicles.

\section{INTRODUCTION}

Road transport is a significant contributor to air pollution and its impact is forecast to increase with growth in motorisation in developing countries. ${ }^{1}$ While vehicle and emissions control technology has improved over the years, ${ }^{2}$ our understanding of the adverse health impact of the pollutants generated has similarly increased. ${ }^{3}$ Modelling of human exposure to these pollutants suggests the need for a more detailed understanding of how driver behaviour and vehicle dynamics influence localised pollution levels. ${ }^{4}$

This paper details the development and testing of a system designed to address this need. The Vehicle Performance and Emissions Monitoring System (VPEMS) project was a collaborative research and development project between the Centre for Transport Studies at Imperial College London and two industrial partners-Sira Ltd and Saturn Technologies Ltdthat ran from 2000 to 2003. The work was sponsored as part of the UK Foresight Vehicle LINK programme, with funding from the Department for Trade and Industry (DTI) and the
Engineering and Physical Sciences Research Council (EPSRC). The main project objectives were to

(a) specify and justify the requirements for an in-vehicle performance monitor, emission sensor and data transmission service employing state-of-the-art technology

(b) define a functional architecture for the device based on these requirements

(c) define innovative algorithms and hardware technology (physical architecture) to support the functional architecture, making use of existing technology as far as possible

(d) develop, test, and demonstrate a prototype of the VPEMS.

This paper reports on the key testing and validation of the system that was developed. One of the criteria identified was that such a system be suitable for cost-effective deployment on a wide range of vehicles, over a wide range of conditions. The prototype system developed during this project demonstrates that it is possible to produce such a system, but that there remain technical barriers to overcome. In the following sections we first review other work in this area. This is followed by a description of the prototype VPEMS and system validation results. We conclude with some thoughts for future avenues of research.

\section{PREVIOUS ON-BOARD EMISSIONS MONITORING STUDIES}

The issue of how to characterise the emissions from in-use vehicles has been addressed by many groups. Tests using onboard monitoring equipment, also known as portable emissions monitoring systems (PEMS), have shown that the emission factors derived from chassis dynamometer tests over standard drive cycles are not necessarily representative of real-world emissions. ${ }^{5}$ A variety of other factors associated with realworld driving and not represented by the standard type approval tests have been found to influence emission levels including driver aggression, ${ }^{6,7}$ road grade and auxiliary engine loads such as air-conditioning, ${ }^{8}$ and global driving style. ${ }^{9}$ These studies have suggested that better characterisation of emissions inventories can be estimated using on-board measurements, rather than dynamometer tests.

All of the above studies are characterised by a limited sample set of vehicles. To address this and aid the generation of larger data sets, PEMS that can be readily transferred from one 
vehicle to another have been developed and are now marketed commercially.

The Clean Air Technologies International OEM 2100 system measures carbon monoxide $(\mathrm{CO})$ and carbon dioxide $\left(\mathrm{CO}_{2}\right)$ using non-dispersive infrared (NDIR), nitrogen oxides (NO) employing electrochemical cells and particulate matter via a light-scattering technique. System development is described by Vojtisek-Lom and Allsop ${ }^{10}$ and its use for testing gaseous emissions from in-use vehicles is described by Frey et al. ${ }^{11}$ The sample line is not heated. Data issuing from an extensive data collection exercise in North Carolina have been used to investigate the effect of signal timing on vehicle emissions ${ }^{12}$ and the quantification of vehicle emissions hotspots. ${ }^{13}$ Other studies include an investigation of high-occupancy vehicle (HOV) lanes ${ }^{14}$ and measurement of off-highway construction equipment emissions. ${ }^{15}$ This unit seeks to be simple and portable and as such has accepted some trade-offs in terms of accuracy; however, it is alleged that careful post-processing of the data can lead to good agreement between the on-board measurements and a chassis dynamometer test. ${ }^{10}$ Data from this unit can also be integrated with Global Positioning System (GPS) measurements to allow the spatial aspect of the emissions measurements to be investigated.

Sensors Incorporated have a pair of systems-the SEMTECH-G and SEMTECH-D-for use on gasoline- (petrol) and dieselfuelled vehicles respectively. ${ }^{16}$ Both measure second-by-second $\mathrm{CO}$ and $\mathrm{CO}_{2}$ emissions (using $\mathrm{NDIR}$ ) and $\mathrm{NO}_{\mathrm{x}}$ emissions using a non-dispersive ultraviolet (NDUV) system. Hydrocarbon (HC) emissions are measured using a flame-ionisation detector (FID) for SEMTECH-D and NDIR for SEMTECH-G. NDIR cannot resolve all HC emissions (underestimating by approximately 35\%), but the use of FID for the diesel system requires that a heated sample line be used, greatly increasing the power requirements. These systems were used extensively to test 18 passenger cars and 17 diesel buses. ${ }^{16}$ These data sets were used in the US Environmental Protection Agency (EPA) Onboard Analysis Shootout where the issue of how best to incorporate the data from PEMS into the next generation of mobile source emission models was addressed. ${ }^{17}$ The SEMTECH-D system was also used to test two heavy-duty vehicles in the $\mathrm{UK}^{18}$ and established on-board monitoring as a feasible alternative to chassis dynamometer testing for in-service testing of heavyduty vehicles. Some data from a prototype direct exhaust mass flow measuring device were also presented and GPS navigation data can also be integrated with the system.

Horiba Instruments have produced an on-board system, the OBS 1000. A predecessor of this system is described by Kihara. ${ }^{19}$ Oestergaard presents the specification of the 2002 version of the system. ${ }^{20} \mathrm{CO}, \mathrm{CO}_{2}$ and $\mathrm{HC}$ are measured using NDIR, with zirconium oxide $\left(\mathrm{ZrO}_{2}\right)$ sensors being used to detect NO and the air-fuel ratio. One important area of development lies in the direct measurement of the exhaust mass flow rate. This is combined with the measured pollutant concentrations to provide mass emissions. It is normally derived from engine operating parameters rather than being measured directly, which potentially leads to some errors. A number of different techniques for deriving the exhaust mass flow are mentioned including the use of pitot tube and Annubar ${ }^{\mathrm{TM}}$ pressure measurement arrangements. Comparison of the integrated system output to a dynamometer test shows very good agreement, to within approximately $2 \%$. Data are presented showing the integration of the system with GPS measurements. Negative aspects of this system include its size and weight, making it best suited to detailed long-term testing on a single vehicle.

The operating costs associated with each of these systems are a combination of equipment purchase or lease, installation in a given vehicle, and the cost associated with gathering data from a specific test run. While the set-up time in a vehicle may be relatively short, each of these systems stores data on-board, requiring someone to visit the vehicle to download the data. This can impose a substantial cost in terms of operator time, especially for long-term or geographically remote testing. Data recording from these units has apparently been limited to short tests (up to a few hours running at a time) and limited fleet sizes.

A unit designed for longer-term testing is the Simple Portable Onboard Test (SPOT) system developed by the US EPA. ${ }^{21}$ It is aimed primarily at non-road emission sources and features both GPS and mobile telecommunications technologies as well as an innovative method for the direct derivation of exhaust mass flow. It would be attractive to apply this monitoring unit to testing on road vehicles; however, the authors are not aware of any studies that have done so.

There will be an ongoing need for new emissions data as the fleet composition changes and vehicles age to ensure that emissions models are representative of the current in-use fleet and its operation. This is likely to require data from many vehicles operating under a wide variety of conditions. A program of this nature will be labour-intensive and therefore expensive to administer using current PEMS technology. An advance can therefore be made through enabling remote download of data from a device cheap enough and robust enough to be fitted to many vehicles simultaneously and operated over extended periods of time. Other areas, not previously investigated, include the seamless integration of the data into systems for spatial analysis that are the basis of many exposure models. ${ }^{4}$

\section{THE VPEMS PROJECT}

Remote downloading and integrated communications with a central PC was one of the goals of the VPEMS project. The system was designed to potentially enable large-scale deployment and automatic communication and data downloads. One of the initial objectives was to enable the use of the system for fleet management. User service requirements are given in detail by Sheridan et al. ${ }^{22}$ Initial trials of the individual subsystems led to the specification of a full prototype system. ${ }^{23}$ This initial VPEMS design was developed to satisfy the user requirements of fleet managers and as far as possible to be compatible with any vehicle. These requirements are summarised in Table 1.

The two main quantitative criteria were seen as being horizontal positioning of the vehicle to be accurate to within $50 \mathrm{~m} \mathrm{95 \%}$ of the time ( $2 \sigma ; \sigma=$ standard deviation), and mass emission values correct to within $\pm 5 \%$ in terms of both accuracy and bias. 


\begin{tabular}{|lll|}
\hline Category & Data & Description \\
\hline ID & ID number & Vehicle identifier \\
Event & Event marker & Record of delivery, security alert etc. \\
Navigation & Time & Time (hh:mm:ss) \\
& $x$ (east), $y$ (north), $z$ (height) & Position (Cartesian co-ords local or WGS 84) \\
& $V x, V y, V z$, or speed & Velocity (Cartesian co-ords local or WGS 84) \\
Performance & Pedal use: $\sum \mathrm{C}, \sum \mathrm{B}, \% \mathrm{~A}$ & Total clutch and brake presses, accelerator position \\
& Engine speed & Period $>$ threshold rpm \\
& Fuel consumption & Flow rate \\
Emissions & Vehicle speed and distance travelled & If not provided by navigation function \\
& Exhaust: $\mathrm{HC}, \mathrm{CO}, \mathrm{CO}_{2}, \mathrm{NO}, \mathrm{O}_{2}, \mathrm{PMIO}$ & Regulated pollutants and diagnostics \\
& In-cabin: $\mathrm{HC}, \mathrm{CO}, \mathrm{CO}_{2}, \mathrm{NO}, \mathrm{PMIO}$ & Regulated pollutants and diagnostics \\
& & \\
\hline
\end{tabular}

Prototype units were developed to demonstrate the capability to fit the system to vehicles with different technologies. The test vehicles for the initial field trials were a 1997 model Citroën Synergie MPV fitted with a $2 \cdot 0$ litre petrol engine and a 1999 model Ford Focus Estate powered by a 1.8 litre turbo diesel engine. A programme of testing and verification of the prototype system was then conducted, including limited field trials of both vehicles. ${ }^{24}$ In addition, the Ford Focus underwent back-to-back testing at a chassis dynamometer emissions monitoring facility to test the VPEMS against an established benchmark.

The following sections of this paper discuss the development and fitting of the prototype system to the test vehicles and the challenge of integrating the output of the various subsystems to deliver a coherent spatially and temporally referenced database in near real-time.

\section{TESTING OF SUBSYSTEMS}

The VPEMS system comprises two main groups of subsystems (see Fig. 1): in-vehicle subsystems that are fitted to the test vehicle in order to collect the required data, and those that form the control centre where the data are collated, stored and analysed. This section discusses the two groups in turn.

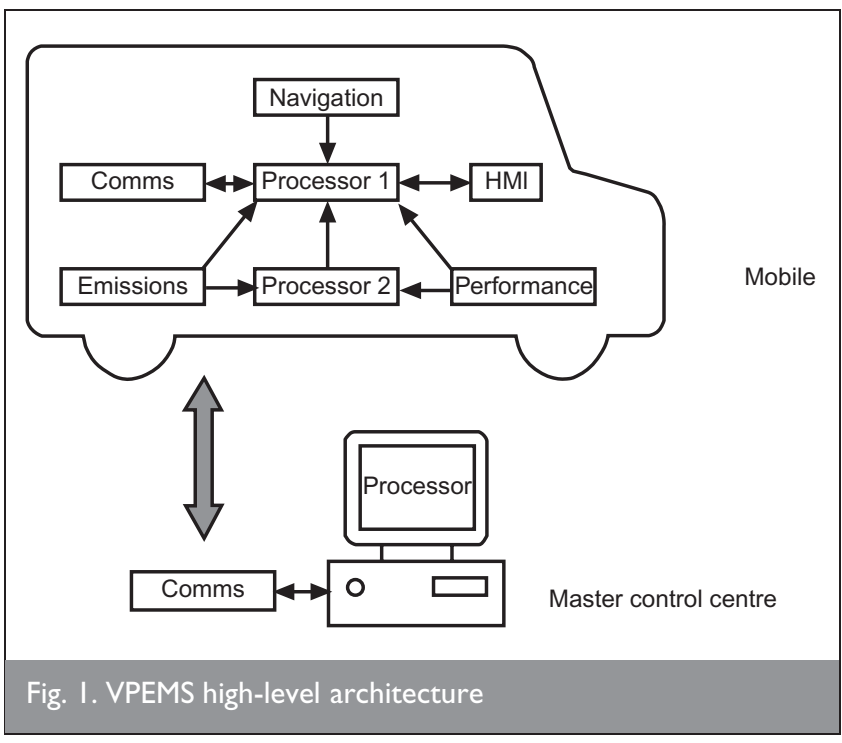

\section{I. In-vehicle subsystems}

4.1.1. Processing. The data processing function for the invehicle subsystem was split into two parts-primary and secondary. The primary processor is a modified version of the Locator II telematics unit marketed by Saturn Technologies. The secondary processor, primarily used for emissions monitoring, was developed in parallel at Sira Ltd. Connectivity between the two processors was achieved by means of a private controller area network (CAN) serial bus system of the type now becoming standard in many vehicle applications (conforming to the SAE standard ${ }^{25}$ ). A different arrangement of the system was devised to suit each of the two test vehicles (see Fig. 2).

On the Ford Focus it was possible to obtain data from the vehicle's own sensor network via the engine management system (EMS). This necessitated an interface with the vehicle's own CAN bus. A processing network with two independent CAN buses was devised to facilitate this connection. This had the advantage of allowing the vehicle CAN bus (CAN bus 2) to be isolated from the VPEMS internal CAN bus (CAN bus 1) thus reducing the risk of interfering with the EMS and vehicle operation. Messages are transmitted on the vehicle CAN at a very high rate (500 kbps), making it necessary to use the

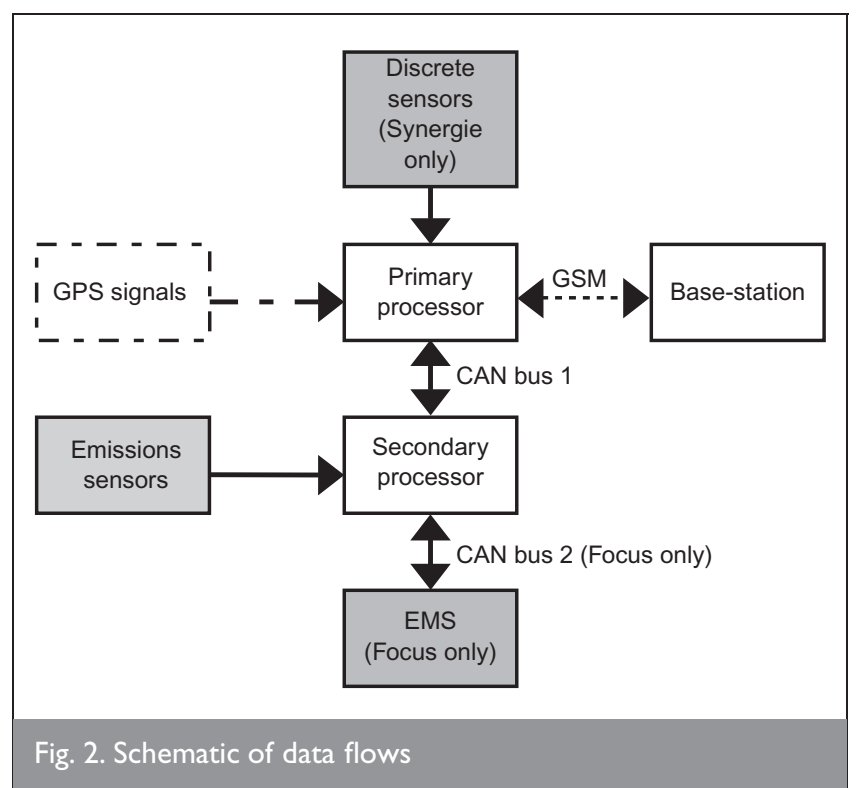


secondary processor to sample and time-stamp the data stream before transmission to the primary unit. The messages could then be decoded into separate data types.

For the Citroën Synergie, an interface to the vehicle EMS was not possible and instead an array of discrete electromechanical sensors was fitted to the vehicle. The vehicle performance data were then logged directly by the primary processor via a series of analogue input lines. The sensors are discussed in more detail below.

The use of two processors is beneficial in terms of system flexibility; however, time synchronisation of data logged by the primary processor and those logged by the secondary processor is required. The navigation subsystem provides an accurate time reference (from GPS) for the primary processor. Sensor data acquired directly by the primary processor (e.g. discrete performance sensor data) is time-stamped using this time reference. The secondary processor will time-stamp the sensor data using its internal clock as the time reference. In order to account for the mismatch between the internal time of the secondary processor and the primary processor/navigation subsystem time, the secondary processor periodically sends a time synchronisation message to the primary processor. The primary processor then adjusts the time-stamp on all data received from the secondary processor by the time difference between the two processors.

4.1.2. Navigation. The navigation function is responsible for the derivation of all spatial, temporal and derivative data on the vehicle including three-dimensional (3D) position, time, speed and acceleration. In light of the preliminary testing of different navigation options, a solution based around a GPS receiver with optional dead reckoning (DR) augmentation was chosen. DR uses distance and heading information, in this case provided by a low-cost micro electro-mechanical systems gyroscope and the vehicle's odometer, to estimate a new position based on the previous position. The combination of the two systems allows an optimal estimation of position to be made by using the GPS signals, when available, to initialise and correct the DR output. ${ }^{26}$ This is especially beneficial in urban areas where GPS availability may be poor due to signalmasking effects.

A comprehensive field test of the navigation subsystem was carried out in the Greater London area in January 2002 to make a credible and realistic assessment and characterisation of the system performance in various configurations. ${ }^{27}$ In this test, the hardware-accelerated VPEMS GPS device was compared to the performance of three other devices: a geodetic GPS unit (capable of centimetric precision); a differential GPS (DGPS) unit; and the output of the Neve GPSi device (featuring GPS augmented with DR) in GPS-only mode. The output of the hardware-accelerated VPEMS GPS was then augmented with data from the Neve DR sensor using extended Kalman filter (EKF) algorithms developed during this project. ${ }^{26}$

The route was chosen carefully to have a good mix of important spatial urban characteristics including open spaces, urban canyons, tall buildings, tunnels, bridges and potential sources of electromagnetic interference. Accuracy is defined by recording the percentage of the total fixes ( $\%$ of total mission) that lie within a specified radius of the reference point. For this study the reference point is taken to be the reading given by the high-precision geodetic receiver. The standalone hardwareaccelerated GPS unit performed surprisingly well in terms of accuracy, and still better when augmented by the DR information. A detailed analysis of this data is given by Zhao et al. ${ }^{26}$

Only measurements of horizontal position were recorded using this system as GPS estimates of height are generally prone to inaccuracy due to a weakness in the geometry of the satellite constellation, made even worse by signal-masking effects in built-up areas. Road grade data could either be obtained from the mapping database in the master control centre or through the addition of extra sensors such as an inclinometer or an altimeter.

The speed measurement (obtained from the Doppler shift of the carrier phase signals) was compared to the output of the wheel sensors. For the Synergie test vehicle, problems were encountered in sampling the speed from the odometer at high speed due to the high data rate overwhelming the primary processor input line. However, for a typical urban test (where it is likely that the GPS performance may be degraded), the wheel speed measurement correlated well with the GPS value, giving an $R^{2}$ (coefficient of determination) value of 0.87 (see Fig. 3), a slope of 0.94 and a standard error of $5.64 \mathrm{~km} / \mathrm{h}$. For the data set presented, no dependence of the standard error on speed is observed. This provides initial internal verification of the performance of both the navigation and performance monitoring subsystems.

4.1.3. Performance. The performance subsystem is responsible for monitoring the vehicle and driver performance data. Both sensor arrays and links to the EMS are used by commercial PEMS to determine vehicle and engine operating parameters. In addition, the service requirements of fleet managers include pedal presses (accelerator, brake and clutch) to allow driver performance to be evaluated. These parameters are not recorded by existing systems. For this study a different approach was adopted for each test vehicle. For the Ford Focus, it was possible to obtain data directly from the vehicle's own sensors via the EMS and a connection to the CAN serial bus whereas for the Citroën Synergie, a variety of

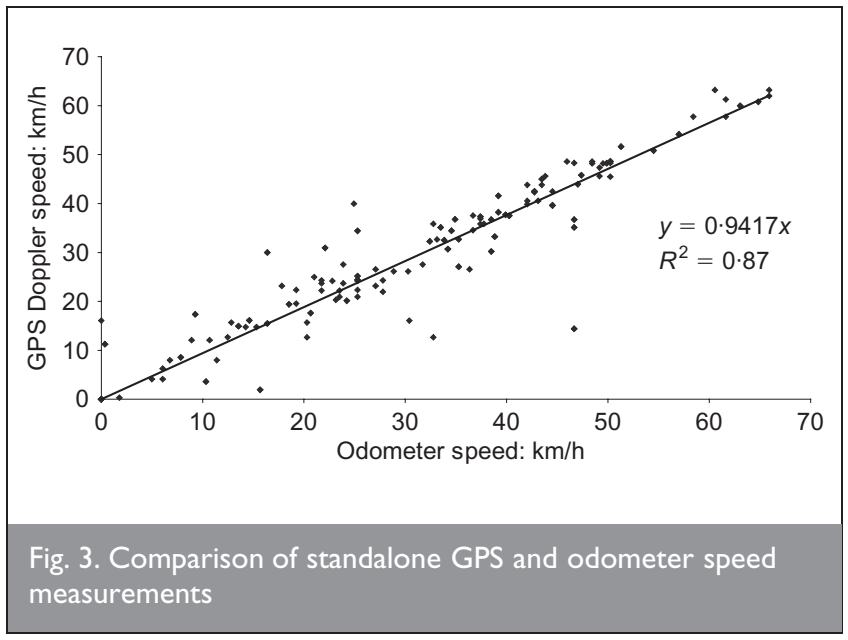


electromechanical sensors had to be fitted.* Due to these differences, the two vehicles are discussed separately below. In both cases, the time and effort required for set-up was significant and the solutions obtained are vehicle-specific. This is a key area for further research and development as a lack of transferability would severely limit the wider application of the technology.

\subsubsection{Ford Focus test vehicle. The use of EMS data for} vehicle performance monitoring is a very attractive option, as it requires a minimum of interference with the vehicle. In the US, standardised on-board diagnostics (OBD) links are fitted to vehicles from model year 1996 and more recently making it relatively straightforward to extract the required data from the EMS. In Europe the European On Board Diagnostics (EOBD) standard was specified by the recent European Directive 98/69/ EC. ${ }^{28}$ Full implementation is required by the 2001 model year (MY) for petrol vehicles, and $2003 \mathrm{MY}$ for diesel vehicles. ${ }^{29}$ Older vehicles may have some of the functionality of these systems but use a variety of physical connectors and proprietary data formats. As a result, different codes may be required even for the same vehicle model featuring different engine management software versions. Manufacturer assistance is therefore vital, but many manufacturers are reluctant to release details of these codes due to commercial sensitivities.

Even with significant assistance from Ford, the process of determining the necessary codes was not straightforward. ${ }^{24} \mathrm{~A}$ diagnostic tool was used to initiate a stream of requested parameters. These were received as blocks of hexadecimal values within a CAN message which required translation and reformatting to retrieve the data.

The sheer volume of data being produced also necessitated the development of the dual-CAN processing architecture previously described (see Fig. 2). The strength of this approach is, however, that the only physical interface to the vehicle required is a pair of wires. Once the software development has been completed, the system can (in theory) be transferred to any vehicle utilising the same EMS software with relatively little fitting work needed. This is of particular interest for fleetmonitoring applications where it is likely that many vehicles of the same type will be operated together.

Due to the difficulty of obtaining further parameters at a later date, more data than necessary were requested from the EMS initially on the basis that this could be filtered later in the system. The following 14 parameters were obtained from the Focus EMS

- accelerator position

- brake use

- clutch use

- road speed $(\mathrm{km} / \mathrm{h})$

- fuel demand (mg per stroke)

- gear

- engine rpm

* EMS interfaces are not yet fully standardised in the European Union. The authors were unable to obtain information from Citroën, but are grateful to the Ford Motor Company for assistance in decoding the data.
- $\quad$ air-conditioning button state

- air-conditioning clutch state

- manifold absolute pressure

- air temperature at inlet

- engine coolant temperature

- fuel tank level

- exhaust gas recirculation valve position.

With this approach it is only possible to select a subset of the metrics that Ford already measure and pass through the EMS. It is also necessary to rely on the performance of the standard sensors installed by Ford.

The Ford Focus was tested on a chassis dynamometer by the Powertrain and Vehicle Research Unit at the University of Bath to provide overall validation of the emissions subsystem. This allowed the output of the EMS 'wheel speed' metric to be compared to the vehicle speed as measured by the dynamometer. Fig. 4 presents the collated data from three standard New European Drive Cycle (NEDC) test cycles after filtering for extreme values. An $R^{2}$ of 0.997, a slope of 1.02 and a standard error of $1.66 \mathrm{~km} / \mathrm{h}$, show an extremely high degree of correlation between the two measurements.

The periodic expansions in the scatter plot correspond to passages where the wheels are accelerating (the lower loops) and decelerating (the upper loops). The effect appears to be less at high speeds. This may be an artefact of dynamic deformation of the tyres under acceleration combined with an assumed constant tyre diameter in the EMS. This may also have been exacerbated by the need to lower the tyre pressures prior to dynamometer testing.

After having successfully interfaced with the EMS, data were obtained to a satisfactory level. However, the proprietary and variable nature of the EMS data formats, especially for older vehicles, renders this method hard to implement widely at present and this presents a significant hurdle for the measurement of detailed driver and vehicle performance data from a European fleet. Once such standards are in place, the time and effort required to obtain these data from a new vehicle type should be minimal.

4.1.3.2. Citroën Synergie test vehicle. The output of each sensor was fed directly into the primary processor via a set of dedicated input lines. The parameters were recorded and their

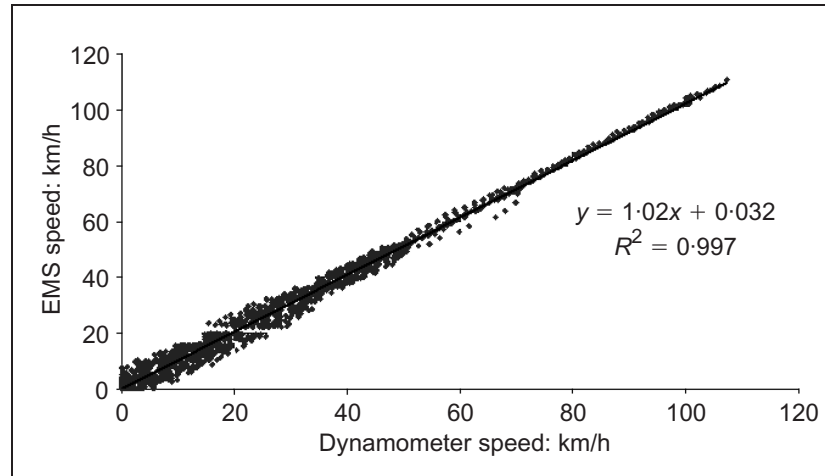

Fig. 4. Dynamometer verification of speed measurements 
methods of measurement are given in Table 2. After testing low-cost fuel flow meters, a high-specification device (an AIC Systems 1204 HR2000) was found to be necessary to gain sufficiently reliable fuel flow measures from the test vehicle. In the absence of other technologies, this would impose a significant cost for a multi-vehicle fleet.

In order to check the performance of each sensor, simple tests were performed against various known vehicle states and the readings from the vehicle's own dials. Further validation work under more controlled circumstances is desirable and is currently being pursued.

Figure 5 shows the data collected for a typical starting and stopping manoeuvre. The pedal positions are the three traces at the bottom of the graph where a 'high' value for the pedal corresponds to it being pressed down. Engine speed and vehicle speed are also included to relate the driver inputs to the engine and vehicle response. Fig. 5 also shows a number of features including a prolonged use of the clutch between $\sim 8 \mathrm{~s}$ and $14 \mathrm{~s}$ while moving off, followed by a brief use of the clutch and release of the accelerator between $15 \mathrm{~s}$ and $18 \mathrm{~s}$ corresponding to the gearshift from first to second. The change back down (at $31 \mathrm{~s}$ ) is masked somewhat by the fact that the clutch is then held depressed until the vehicle stops. At both ends of the manoeuvre the engine returns to its idle speed of approximately $840 \mathrm{rpm}$. The sharp drop in engine speed at $17 \mathrm{~s}$ represents a gearshift from first to second. The corresponding rise at $31 \mathrm{~s}$ represents the change down from second to first with the right foot moving to the brake pedal and the engine being used to slow the vehicle. Although the clutch remains 'pressed' during this phase, it was released sufficiently for the engine to re-engage with the gearbox and cause the engine speed to rise. This highlights a limitation of using a binary switch to record the clutch pedal use.

The array of sensors on the Synergie was successful in measuring all of the parameters deemed necessary for fleet management to an adequate level of precision. It may be possible to reduce these costs by refining the design of the array, or by monitoring a somewhat reduced set of parameters. However, on the grounds of cost and labour-intensive fitting, the use of discrete sensors is a far less attractive option than EMS connectivity (if available), especially for experiments featuring multi-vehicle fleets.

4.1.4. Emissions. The emissions subsystem was developed to be common to both petrol- and diesel-fuelled vehicles. In both cases the same species are monitored although the relative levels of the different pollutants are different. At different stages in the development process a variety of instruments were incorporated into the system, including a custom-built

\begin{tabular}{|lll|}
\hline Parameter & Sensor type & Resolution \\
\hline Accelerator position & Single potentiometer on throttle spindle & $0.5 \%($ I00\% $=$ fully pressed $)$ \\
Brake presses & Connection to brake light electrical supply & On/off \\
Clutch presses & Switch fitted to pedal & On/off \\
Engine speed & Inductive sensor on HT (spark plug) lead & Speed dependent \\
Wheel speed & Signal taken from vehicle odometer cable & Speed dependent \\
Fuel flow & Fuel flow meter fitted in injector supply line & $0.5 \mathrm{ml}$ \\
& & \\
\hline Table 2. Vehicle performance parameters in the Citroën Synergie test vehicle & \\
\hline
\end{tabular}

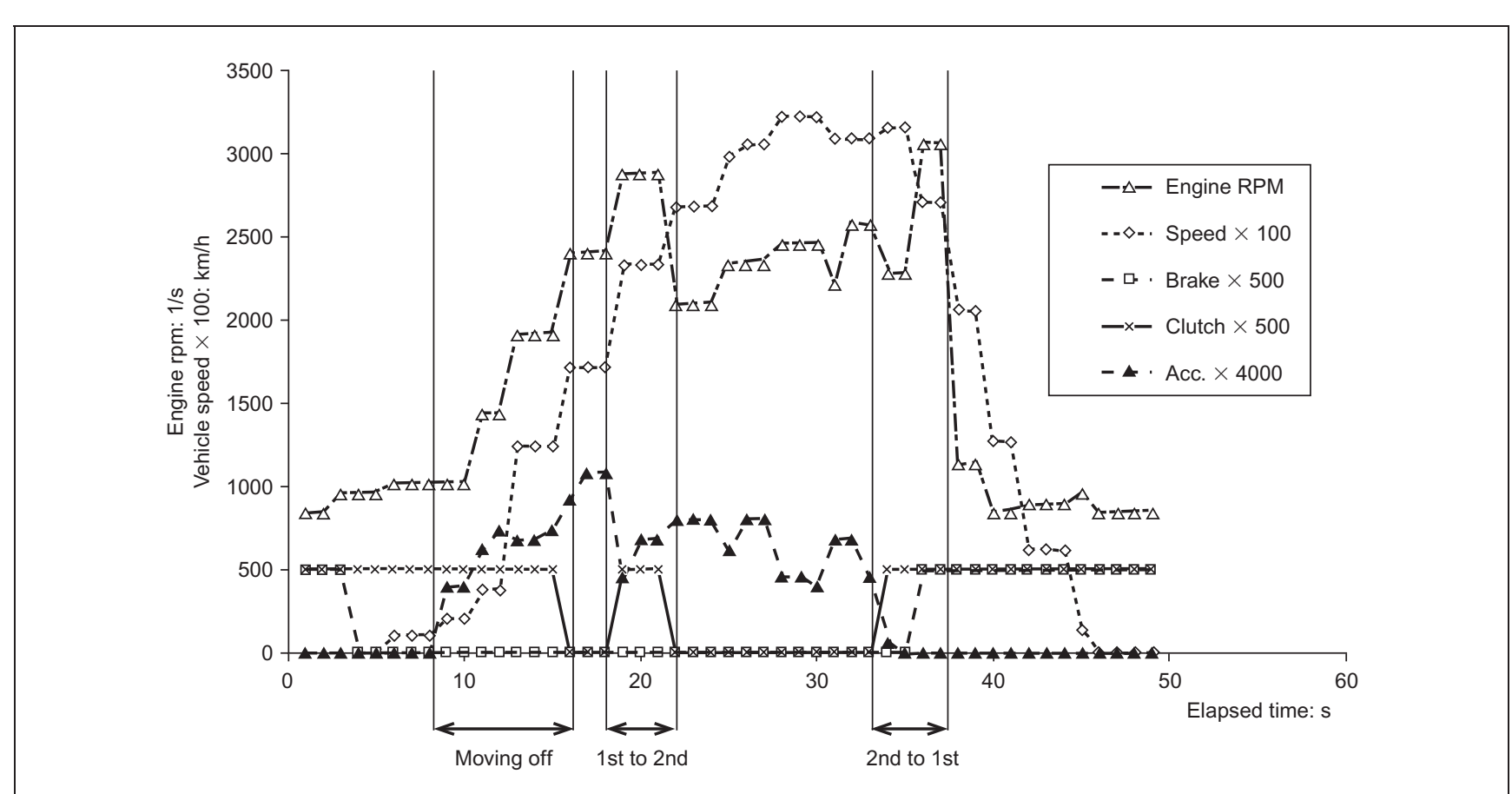

Fig. 5. Pedal positions, engine RPM and vehicle speed for a typical start/stop sequence 
spectrograph and a sensor that measures relative air quality. This section focuses on the development and testing of the core system; based around an Iridium 100 five-gas analyser bench from City Technologies, certified by the California Board of Auto Repair to their BAR-97 standard. A simple particulate monitoring device, measuring the change in optical opacity due to the flow of gas past it, was also incorporated.

4.1.4.1. Gas conditioning. Before the exhaust can be passed through the analyser it must be filtered and dried to remove excessive particulate matter and water vapour. Heated sample lines were not used due to their high power requirements. This is similar to the philosophy adopted by Clean Air Technologies for their OEM 2100 device. The gas conditioning process involved extracting a representative exhaust sample normal to the flow from an attachment fitted to the end of the tailpipe. It is then passed through a $7 \mu \mathrm{m}$ filter, and dried by passing through a Naphion-impregnated tube. Naphion (a polytetrafluoroethylene variant) establishes a humidity gradient between the sample gas and the outside air, effectively drawing water in the vapour out of the sample tube. This process was accelerated by returning a portion of the sample gas through a needle valve and past the outside of the Naphion tube. The overall sample tube length upstream of the analyser was only $1.5 \mathrm{~m}$. The sample flow rate was measured at around 1.51 per minute. The system performed well during the dynamometer test program; however, its long-term performance and durability requires additional testing.

For the prototype system, the analyser was fitted in the cabin. The sample line therefore had to pass from the outside of the vehicle into the cabin, and then return the sample gas to the exterior after measurement. Due to the small diameter (6 $\mathrm{mm}$ ) of the unheated sample lines, minimal alteration to the vehicle was required. The line may be passed through a window or a small ( $\sim 15 \mathrm{~mm}$ diameter) access hole. In order to reduce potential difficulties with condensation, the drying system was placed as close as possible to the extraction point. On the Citroën this involved mounting the dryer under the car body and drilling a hole, whereas a pre-existing hole in the Ford bodyshell made mounting the drying apparatus in the cabin more convenient. A standard fitting procedure would be desirable for future applications.

4.1.4.2. Bench testing. The iridium bench uses NDIR detection to measure $\mathrm{CO}, \mathrm{CO}_{2}$ and $\mathrm{HC}$ concentrations of the sample via the absorption of particular wavelengths of infrared. Electrochemical cells are used to measure $\mathrm{NO}$ and $\mathrm{O}_{2}$. This NO value may then be converted to a $\mathrm{NO}_{\mathrm{x}}$ equivalent if desired. The bench could be operated in one of two modes

(a) compensated, where the bench calculates a parts per million (ppm) concentration value based on an internal compensation algorithm

(b) raw, where the raw signal outputs were returned.

For the initial testing phase, the compensated mode was used.

Thorough testing of the iridium bench was conducted in the laboratory using a series of standardised Ministry of Transport
(MOT) test calibration gas mixtures containing known proportions of $\mathrm{CO}, \mathrm{CO}_{2}, \mathrm{O}_{2}$ and propane $\left(\mathrm{C}_{3} \mathrm{H}_{8}\right)$. A limited amount of NO testing was also carried out using a mixture of known concentration mixed in-house. Discrepancies between the observed levels and the known concentrations of the standards were found to be within the manufacturers' specifications. ${ }^{30}$ These experiments were repeated with the units mounted in the vehicles. The same performance levels were observed, confirming that the analysers worked when being run from the vehicle power supply.

4.1.4.3. Dynamometer testing. After verification tests on both vehicles had confirmed that the prototype system returned broadly sensible values for each of the measured species, the Ford Focus was taken to the University of Bath for testing at the Powertrain and Vehicle Research Unit. Their chassis dynamometer employs industry standard Horiba MEXA 7000 series analysers and can be taken to provide a robust baseline measurement for comparison to the VPEMS sensors. The factory calibration settings for the VPEMS sensors were used along with the gas conditioning system previously described.

A direct comparison of the raw concentration data provided by the two systems over a standard NEDC test cycle was made (1212 s of data after cleaning). A linear regression of the VPEMS concentration measurement of each emitted pollutant (CO (ppm), $\mathrm{CO}_{2}(\%)$ and NO (ppm)) against the reference data was carried out. Drift over time was observed for the CO readings, possibly due to accumulated deposits in the analyser, so the elapsed time was also included for this species. This gave an equation of the form

\begin{tabular}{|l|l|}
\hline Reference conc. $=$ gain (VPEMS conc.) \\
+ gamma (elapsed time in s) + offset
\end{tabular}

Results are shown in Table 3. The addition of the timedependent term for CO improved the adjusted $R^{2}$ from $0 \cdot 84$ to $0 \cdot 94$. These results, as shown by the high $R^{2}$ values, show that there is good correlation between the VPEMS measurements and those measured by the Horiba MEXA 7000 analyser. The gain would ideally approach unity, making the recorded NO measurements somewhat suspicious. The offset would ideally be zero in each case.

These coefficients were then applied to the data collected over another standard NEDC test. Accumulated mass emissions for the two sets of concentration data were calculated using the reference exhaust mass flow, as measured by the dynamometer system (CVS). This allows the impact of using a repair-grade analyser for determination of exhaust concentrations on the measurement of mass emissions to be seen in isolation. The accumulated mass emitted over the cycle agrees very well for $\mathrm{CO}_{2}$ (VPEMS underestimates by $8 \%$ relative to the aggregate bag measurement), but less well for $\mathrm{CO}(11 \%)$ and $\mathrm{NO}_{\mathrm{x}}(18 \%)$.

Further testing and a more detailed analysis of the data obtained will enable robust calibration factors to be derived and an assessment of any deterministic drift in the analyser outputs with respect to time and other variables. This is 


\begin{tabular}{lcccc}
\hline Species & Gain & Gamma & Offset & Adjusted $R^{2}$ \\
\hline $\mathrm{CO}$ & $0.85(111.4)$ & $-0.43(-48.7)$ & $-61.5(-6.1)$ & 0.95 \\
$\mathrm{CO}_{2}$ & $0.96(113.6)$ & - & $-0.26(-6.0)$ & 0.91 \\
$\mathrm{NO}$ & $0.15(159.9)$ & - & $13.8(16.5)$ & 0.95 \\
\hline
\end{tabular}

$t$-statistics are in parentheses

Table 3. Comparison of VPEMS and chassis dynamometer concentration readings between the nephalometer output and particulate matter emissions.

\subsubsection{Communications. A} standard global system for the mobile (GSM) circuit switched data (CSD)-based download method was adopted. This is well-proven technology and has been

especially important for extended field operation of these units without maintenance and may also help to satisfy the measurement accuracy target of $\pm 5 \%$ for each species.

4.1.4.4. Particulates. Several research groups have addressed the question of measuring particulate matter emission from inuse vehicles. Tong et al. used a standard smoke opacity meter, ${ }^{31}$ as used in many regulatory tests, with some success although smoke tests have been shown to correlate poorly with particulate mass emissions. Laser light-scattering techniques show a good correlation with mass emissions and have now been developed into a commercially available system by Clean Air Technologies. All of these techniques measure a sample of the flow that they assume to be representative, which could potentially lead to inaccuracy.

For the prototype VPEMS devices a simple nephalometer system based around changes in the obscuration of an LED source due to the presence of optically opaque matter in the flow was devised. It was designed to mount across the end of the tailpipe, thereby directly measuring the whole gas stream rather than just a sample. After bench testing to establish the temperature dependency of the photodiode, correction algorithms were developed.

Field trials were conducted in parallel to other emissions species. Fig. 6 shows the variation over time of the output of the nephalometer versus acceleration and accelerator position for a short run in the gasoline-fuelled test vehicle in stop and start traffic through Hyde Park. Nephalometer units were based on quantities in direct proportion to higher flow opacity, but otherwise are arbitrarily set.

It can be seen that the significant peak in obscuration (at around $150 \mathrm{~s}$ ) occurs just after the vehicle has undergone an abrupt deceleration followed by a sharp acceleration. The observed time lag and spreading of the peak could perhaps be explained by diffusion and mixing processes occurring in the exhaust system. Initial results are encouraging although more development and testing work is needed on this component of the system to establish the relationship

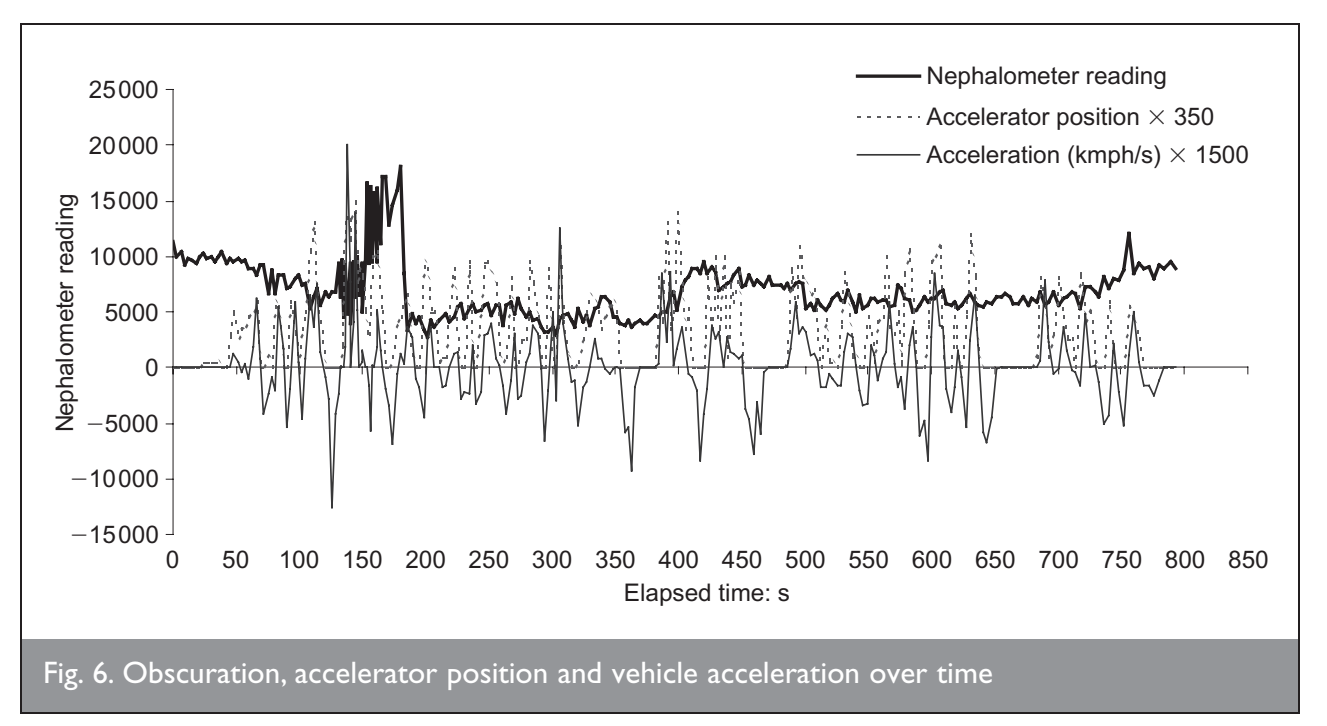


automotive electrical loads such as headlights ( $\sim 90 \mathrm{~W}$ on low beam) or the radio $(\sim 20 \mathrm{~W})^{32}$ and therefore should not significantly influence the operating behaviour of the vehicle. The Locator II unit also features a supplementary battery to prevent the variable supply from the vehicle causing system shutdown. To avoid any influence of the VPEMS power drain on the vehicle behaviour during tests on the chassis dynamometer, the system was powered by an independent $12 \mathrm{~V}$ battery.

During the development phases of the project the power supply was augmented with a second high-capacity battery and an inverter rated to $600 \mathrm{~W}$. The resulting $240 \mathrm{~V}$ supply could then be used to run diagnostic equipment (such as oscilloscopes and monitors) in parallel to the VPEMS, for testing and validation purposes. Data acquired during these runs cannot be taken to be representative of the normal emission levels of the vehicle as the extra load may have induced enrichment leading to higher emissions.

\subsection{Control centre}

The control centre of the VPEMS was based around a highspecification PC fitted with a dual-band GSM modem.

4.2.1. Processor and database. Saturn Technologies Limited's commercially available Sentry software interface was adapted to enable it to recognise the additional messages logged by the VPEMS units and to enable the output of data formatted to suit the needs of the operator. Sentry receives the log file from the in-vehicle processor, sorts the messages according to their time stamp and then creates a database of coherent observations. For the initial development phase, the MS Access database format was used, with further conversion to MS Excel format for more detailed analyses and post-processing operations (e.g. calculation of emissions factors). Post-processing functions could be incorporated into Sentry, but this was not implemented for the prototype system as the improved transparency of the data processing and speed of report generation were found to be helpful when diagnosing system faults during the development phase of the project. Over the course of extended field trials with Saturn's existing customer base, Sentry has proven to be reliable and readily adaptable to suit new requirements.

\subsubsection{Navigation. The navigation subsystem at the control} centre takes the positional data supplied by the in-vehicle subsystem and combines it with a digital database. To reconcile the errors associated with both the position calculated by the in-vehicle navigation system and the digital map, an advanced map-matching technique has been developed during this project. ${ }^{33}$ The performance of the algorithm is found to be exceptional for complex urban road networks. It has been found that the newly developed map-matching algorithm not only reconciles the inaccurate locational data with inaccurate digital road network data but also improves the accuracy of the vehicle position. The standard deviation of the error is reduced from values of 16-20 m to 4-5 $\mathrm{m}$ for both easting and northing components of position. This operation was performed during post-processing in the prototype system.

\section{INTEGRATION OF OTHER SENSORS: RELATIVE CABIN AIR QUALITY}

The VPEMS architecture was developed to support the addition of further on-board sensors to monitor other variables of interest such as in-cabin exposure to pollutants in parallel with vehicle performance and tailpipe emissions measurements. Incabin exposure to pollutants (especially particulates) has been addressed in more detail elsewhere. ${ }^{34,35}$ During the development phase of VPEMS, a simple air quality monitor (AQM) was incorporated to demonstrate the possibility of measuring in-cabin exposure. The AQM returns a simple level of relative air quality based on levels of oxidising gases (e.g. CO) and reducing gases (e.g. NO) present in the air. ${ }^{36}$ It was tested on a route from Imperial College London in South Kensington along the A4 and M4 towards Heathrow Airport. The evolution of relative cabin air quality was thereby assessed over the transition from urban streets to open motorway. Fig. 7 clearly shows the expected pattern of acceleration in urban conditions versus free-flowing conditions on a less congested motorway.

Although this measure of relative change in air quality is not

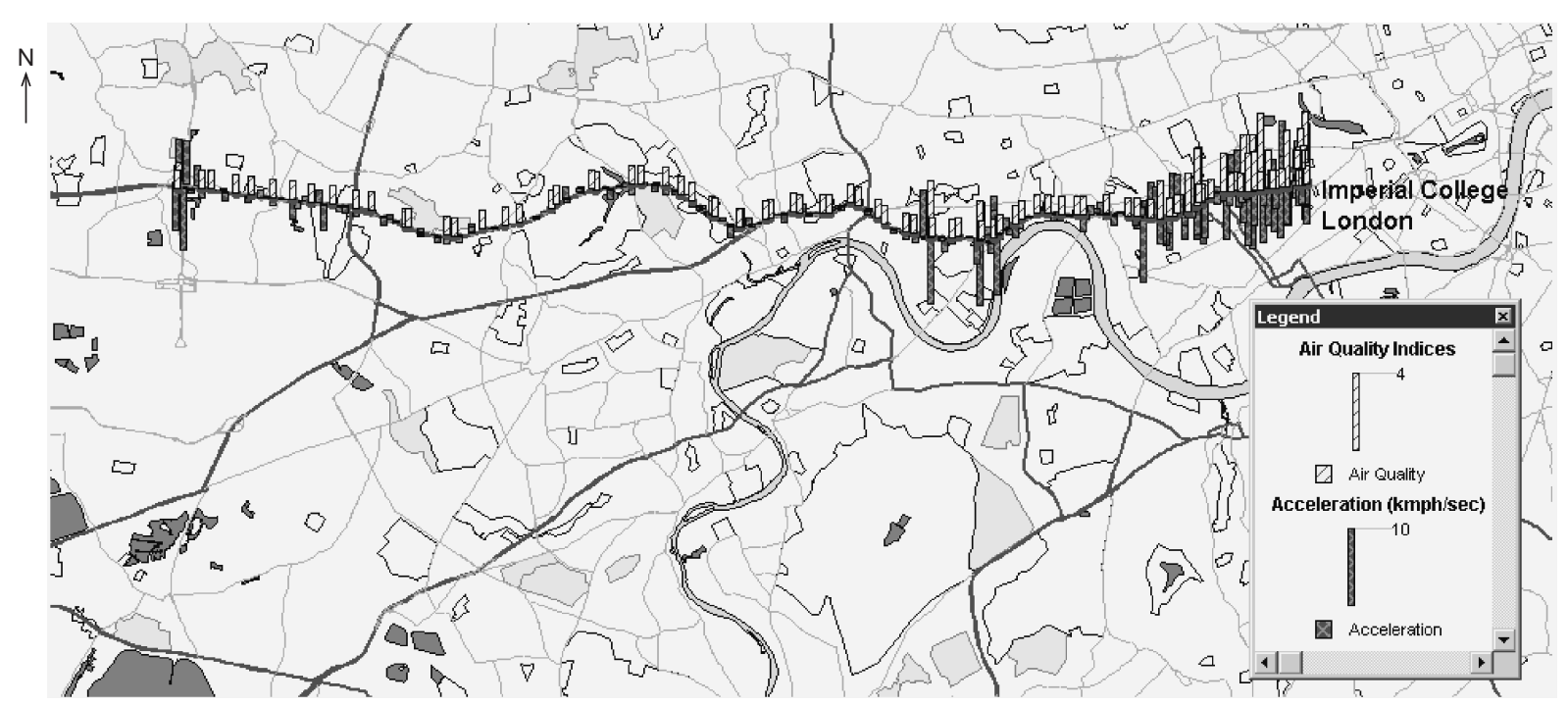

Fig. 7. In-cabin air quality monitor output over test route (scale, I :2500) 
quantitative it is clear that there is a significant change in typical cabin exposure levels between open highway and congested urban driving conditions. There also appears to be some correlation with vehicle acceleration. This figure also illustrates the expected relationships between congested road and high accelerations and free-flow traffic being associated with relatively constant speeds. The integration of more advanced monitoring systems will be pursued with future versions of the VPEMS system.

\section{CONCLUSIONS}

After an extensive study of the requirements for an in-vehicle performance monitor, emission sensor and data transmission service, a functional architecture has been defined and presented. The VPEMS prototype system has been successfully installed and demonstrated on two test vehicles featuring different fuel and data acquisition technologies. Spatially and temporally referenced pollutant and driver/vehicle performance data, including pedal presses and gear changes, have been collected from both vehicles during field trials and downloaded to a remote computer in near real-time. Testing of the individual subsystems and back-to-back testing on a chassis dynamometer show good correlation of measurements, although some drift in the instruments was observed. The system demonstrates the feasibility of providing the data types identified as necessary for fleet management from a compact and low-power unit.

Obtaining detailed vehicle performance data is not straightforward for many vehicles in the European fleet. Engine management system (EMS) software interfaces are not yet fully standardised, making connectivity vehicle-specific. The alternative method of fitting an array of sensors was found to be expensive in terms of both labour and parts. The European Directive 98/69/EC requires vehicle manufacturers to adopt standard EMS interfaces for new vehicles. It is recommended that this be fully implemented and enforced as soon as possible, with the information being made publicly available.

Remote download of data to a central base-station is an attractive technique for collecting data from multiple vehicles simultaneously, especially when conducting long-terms tests, or tests on vehicles operating in remote areas. Reducing the unit cost of the monitoring system, simplifying the installation process and understanding the long-term behaviour of the instrument are key factors in making such wide-scale testing feasible.

To achieve these aims, further development and more extensive validation of the prototype VPEMS are necessary. Development work is ongoing, and the system fitted to the existing pair of test vehicles will be used both to further refine the system and to inform a variety of research areas, such as the use of PEMS as a supplement to modelling and in the investigation of the impact of driver behaviour on emissions.

\section{ACKNOWLEDGEMENTS}

The authors gratefully acknowledge the financial support of this project from the UK Department of Trade and Industry and the Engineering and Physical Sciences Research Council through the UK Foresight Vehicle LINK scheme. Thanks also go to all members of the VPEMS team, at Imperial College London
(Professor David Briggs, Professor Paul Elliott and Dr John Gulliver), at Sira Limited (Dr Lesley Hanna and Dr Ruthven Evans), and Saturn Technologies Limited (William Reid and Chris Miller).

\section{REFERENCES}

1. Colvile R. N., Hutchinson E. J., Mindell J. S. and WARren R. F. The transport sector as a source of air pollution. Atmospheric Environment, 2001, 35, No. 9, 1537-1565.

2. Pokharel S. S., Bishop G. A. and Stedman D. H. Emissions reductions as a result of automobile improvement. Environmental Science and Technology, 2003, 37, No. 22, 5097-5101.

3. Bernstein J. A., Alexis N., Barnes C., Bernstein I. L., Nel A., Peden D., Diaz-Sanchez D., Tarlo S. M. and Williams P. B. Health effects of air pollution. Journal of Allergy and Clinical Immunology, 2004, 114, No. 5, 1116-1123.

4. Gulliver J. and BRIGgS D. J. Time-space modeling of journey-time exposure to traffic-related air pollution using GIS. Environmental Research, 2005, 97, No. 1, 10-25.

5. St Denis M. J., Cicero-Fernandez P., Winer A. M., Butler J. W. and JESION G. Effects of in-use driving conditions and vehicle/engine operating parameters on 'off-cycle' events: comparison with federal test procedure conditions. Journal of the Air and Waste Management Association, 1994, 44, No. 1, 31-38

6. De Vlieger I. On-board emission and fuel consumption measurement campaign of petrol-driven passenger cars. Atmospheric Enmvironment, 1997, 31, No. 22, 3753-3761.

7. NAM E. K. GIERCZAK C. A. and BUtLer J. W. A comparison of real-world and modelled emissions under conditions of variable driver aggressiveness. Proceedings of the $83 \mathrm{rd}$ Transportation Research Board Annual Meeting, Washington DC, 2003.

8. Cicero-Fernandez P., Long J. R. and Winer A. M. Effects of grades and other roads on on-road emissions of hydrocarbons and carbon monoxide. Journal of the Air and Waste Management Association, 1997, 47, No. 8, 898-904.

9. Holmen B. A. and Niemeier D. A. Characterizing the effects of driver variability on real-world vehicle emissions. Transportation Research D, 1998, 3, No. 2, 117-128.

10. VoJTiseK-Lom M. and Allsop J. E. Development of heavyduty diesel portable, on-board mass exhaust emissions monitoring system with $\mathrm{NO}_{\mathrm{x}}, \mathrm{CO}_{2}$ and qualitative $\mathrm{PM}$ capabilities. Society of Automotive Engineers, Warrendale PA, 2001, SAE Technical Paper 2001-01-2641.

11. Frey H. C., Rouphail N. M., UnAl A. and Colyar J. D. Onroad measurement of vehicle tailpipe emissions using a portable instrument. Journal of the Air and Waste Management Association, 2003, 53, No. 8, 992-1002.

12. Unal A., Frey H. C., and Rouphail N. M. Effect of arterial signalisation and level of service on measured vehicle emissions. Transportation Research Record, 2003, No. 1842, $47-56$.

13. Unal A., Frey H. C. and Rouphail N. M. Quantification of vehicle emissions hot spots based upon on-board measurements. Journal of the Air and Waste Management Association, 2004, 54, No. 2, 130-140.

14. Rillet L. R., ZietSMAn J., Kim S.-J. and TYLDLACKA J. Portable emissions measurement systems: lessons learned. 
Proceedings of the 84th Annual Meeting of the Transportation Research Board, Washington DC, 2004.

15. VoJTISEK-LOM M. and WiLSON P. J. Real-world, In-use Exhaust Emissions from Front-end loaders Equipped with Continuously Regenerating Diesel Particulate Filters (DPF) at the World Trade Center Site. Clean Air Technologies report to M.J. Bradley and Associates, October 2003. Available at: http://www.cleanairt.com/download/ wtc_crt.pdf

16. ENSFIELD C. On-road Emissions Testing of 18 Tier 1 Passenger Cars and 17 Diesel-powered Public Transport Buses. Assessments and Standards Division, Office of Transportation and Air Quality, US Environmental Protection Agency, Washington, DC, 2002, EPA Report EPA420-R-02-030.

17. HART C., Koupal J. and Giannelli R. EPA's Onboard Emissions Analysis Shootout: Overview and Results. Assessments and Standards Division, Office of Transportation and Air Quality, US Environmental Protection Agency, Washington, DC, 2002, EPA report EPA420-R-02-026.

18. Rowlands S. C., Macey B. E., Calvert R. J. and Parkin C. Development of On-track Chassis Dynamometer Drive Cycles and Subsequent Evaluation of Sensors Europe Onboard Emissions Sampling System. Millbrook Proving Ground Report MBK 03 /0592 to the UK Department for Transport.

19. Kinara N., Tsukamoto T., Matsumoto K., Ishida K., Kon M. and MURASE T. Real-time, On-board Measurement of Mass Emission of $\mathrm{NO}_{x}$, Fuel Consumption, Road Load, and Engine Output for Diesel Vehicles. Society of Automotive Engineers, Warrendale PA, USA, 2000, SAE Technical Paper 2000-01-1141.

20. OestergaARD K. The Horiba approach to on-board emissions monitoring. Proceedings of the Mobile Sources Technical Review Subcommittee, Alexandria, Virginia, February 2002. Available at: http://www.epa.gov/air/caaac/ oestergaard.pdf

21. FULPER C. Portable emission measurement strategy. Proceedings of the Mobile Sources Technical Review Subcommittee, Alexandria, Virginia, February 2002. Available at: http://www.epa.gov/air/caaac/fulper.pdf

22. SHeridAn K., Ochieng W. Y. and Noland R. B. The Vehicle Performance and Emissions Monitoring System Service Requirements Document (SRD), 2000. Available at: http:// www.geomatics.cv.ic.ac.uk/

23. Evans R., Crookell A., Ochieng W. Y., Sheridan K., Walker M., Randolph W., PolaK J. W., Noland R. B. and BRiggs D. The Vehicle Performance and Emissions Monitoring System Design Document, 2001. Available at: http:// www.geomatics.cv.ic.ac.uk/

24. North R. J., Evans R., Miller C. M., Ochieng W. Y., Quddus
M. A., Noland R. B. and Briggs D. The Vehicle Performance and Emissions Monitoring Testing and Data Analysis Document, 2003. Available at: http://www. geomatics.cv.ic.ac.uk/

25. Society of Automotive Engineers. Recommended Practice for a Serial Control and Communications Vehicle Network. SAE, Warrendale, PA, 2005, standard J1939.

26. Zhao L., OChIENG W. Y., Quddus M. A. and Noland R. B. An extended Kalman Filter algorithm for integrating GPS and low cost Dead Reckoning system data for vehicle performance and emissions monitoring. Journal of Navigation, 2003, 56, No. 2, 257-275.

27. Ochieng W. Y., Noland R. B., Polak J. W., Park J.-H., Zhao L., Briggs D., CROOKell A., Evans R., WALKer M. and RANDOLPH W. Integration of GPS and dead reckoning for real time vehicle performance and emissions monitoring. The GPS Solutions Journal, 2003, 6, No. 4, 229-241.

28. EUROPEAN PARLIAMENT and COUNCIL OF THE EUROPEAN UNION. Directive 98/69/EC of the European Parliament and of the Council of 13 October 1998 relating to measures to be taken against air pollution by emission from motor vehicles and amending Council Directive 70/220/EEC. Official Journal of the European Communities, 1998, L350/1.

29. NorRis J. O. W. and READING A. H. An In-service Emissions Test for Spark Ignition (SI) Petrol Engines-Phase $2 a$ Report, an Evaluation of the Significance of OBD/OBM. Report to the UK Department for Transport Project PPAD 9/107/09, September 2002.

30. City Technology. Iridium 100 Product Specification Sheet; Iridium 100.pmd Version 1·6. City Technology Ltd, Portsmouth, 2002.

31. Tong H. Y., Hung W. T. and Cheung C. S. On-road motor vehicle emissions and fuel consumption in urban driving conditions. Journal of the Air and Waste Management Association, 2000, 50, No. 4, 543-554.

32. MeYer F. Automotive Electrical Systems in Bosch Automotive Handbook, 5th edn. Robert Bosch GmbH, Stuttgart, 2000.

33. Quddus M. A., Ochieng W. Y., Zhao L. and Noland R. B. A general map matching algorithm for transport telematics applications. GPS Solutions, 2003, 7, No. 3, 157-167.

34. GULLIVER J. and Briggs D. J. Personal exposure to particulate air pollution in transport microenvironments. Atmospheric Environment, 2004, 38, No. 1, 1-8.

35. Adams H. S., NieuWenhuiJsen M. J., Colvile R. N., McMullen M. A. S. and KhandelWAl P. Fine particle (PM2.5) personal exposure levels in transport microenvironments, London, UK. The Science of The Total Environment, 2001, 279, Nos 1-3, 29-44.

36. First Technology. Air Quality Module Data Sheet. First Technology, Southfield, MI, USA, 2003, Document No. 25032.

\section{What do you think?}

To comment on this paper, please email up to 500 words to the editor at journals@ice.org.uk

Proceedings journals rely entirely on contributions sent in by civil engineers and related professionals, academics and students. Papers should be 2-5000 words long, with adequate illustrations and references. Please visit www.thomastelford.com/journals for author guidelines and further details. 